\title{
Cannabinoid Type 1 Receptor Antagonists Modulate Transport Activity of Multidrug Resistance-Associated Proteins MRP1, MRP2, MRP3, and MRP4
}

\author{
Hanneke G. M. Wittgen, Jeroen J. M. W. van den Heuvel, Petra H. H. van den Broek, \\ Heike Dinter-Heidorn, Jan B. Koenderink, and Frans G. M. Russel
}

Department of Pharmacology and Toxicology, Radboud University Nijmegen Medical Centre, Nijmegen Centre for Molecular Life Sciences, Nijmegen, The Netherlands (H.G.M.W., J.J.M.W.v.d.H., P.H.H.v.d.B., J.B.K., F.G.M.R.); and Abbott Products $\mathrm{GmbH}$, Hannover, Germany (H.D.-H.)

Received December 15, 2010; accepted April 21, 2011

\section{ABSTRACT:}

Cannabinoid type 1 (CB1) receptor antagonists have been developed for the treatment of obesity, but a major disadvantage is that they cause unwanted psychiatric effects. Selective targeting of peripheral CB1 receptors might be an option to circumvent these side effects. Multidrug resistance-associated proteins (MRPs) can influence the pharmacokinetics of drugs and thereby affect their disposition in the body. In this study, we investigated the interaction of the prototypic CB1 receptor antagonist rimonabant and a series of 3,4-diarylpyrazoline CB1 receptor antagonists with MRP1, MRP2, MRP3, and MRP4 in vitro. Their effect on ATP-dependent transport of estradiol 17- $\beta$-D-glucuronide $\left(E_{2} 17 \beta G\right)$ was measured in inside-out membrane vesicles isolated from transporter-overexpressing human embryonic kidney 293 cells. Rimonabant inhibited MRP1 transport activity more potently than MRP4 $\left(K_{\mathrm{i}}\right.$ of 1.4 and 4 $\mu \mathrm{M}$, respectively), whereas the 3,4-diarylpyrazolines were stronger inhibitors of MRP4- than MRP1-mediated transport. A number of CB1 receptor antagonists, including rimonabant, stimulated MRP2 and MRP3 transport activity at low substrate concentrations but inhibited $E_{2} 17 \beta G$ transport at high substrate concentrations. The interaction of 3,4-diarylpyrazolines and rimonabant with MRP1-4 indicates their potential for drug-drug interactions. Preliminary in vivo data suggested that for some 3,4-diarylpyrazolines the relatively lower brain efficacy may be related to their inhibitory potency against MRP4 activity. Furthermore, this study shows that the modulatory effects of the 3,4-diarylpyrazolines were influenced by their chemical properties and that small variations in structure can determine the affinity of these compounds for efflux transporters and thereby affect their pharmacokinetic behavior.

\section{Introduction}

The cannabinoid type 1 (CB1) receptor is involved in regulation of feeding behavior, metabolism and energy balance (Di Marzo, 2008). Studies in rodents have shown that antagonism of this receptor leads to reduced food intake and weight reduction (Boyd and Fremming, 2005). Several CB1 receptor antagonists were developed for the treatment of obesity, and clinical studies showed a reduction in appetite, weight loss, and improved metabolic risk factors (Boyd and Fremming, 2005; Bifulco et al., 2009). Rimonabant was the first and only selective CB1 receptor antagonist approved for therapeutic use. However, the drug was withdrawn from the market within 2 years of its introduction, because psychiatric adverse effects, in particular depression, were revealed in additional clinical studies (Jones, 2008; Nissen et al., 2008).

The CB1 receptor is expressed in brain and peripheral tissues such as adipose, skeletal muscle, liver, gut, and pancreas (Di Marzo, 2008).

This work was supported by the Dutch Top Institute Pharma [Project T5-105]. Article, publication date, and citation information can be found at http://dmd.aspetjournals.org.

doi:10.1124/dmd.110.037812.
In the brain, activation of the endocannabinoid system appears to be involved in coping with stress and anxiety. Therefore, the psychiatric side effects seen for $\mathrm{CB} 1$ receptor antagonists could be due to inhibition of the endocannabinoid system (Bifulco et al., 2009). It is believed that the positive effect of antagonists on metabolic factors could also be mediated via peripheral CB1 receptors (Di Marzo, 2008). Indeed, a recent study with a peripheral CB1 receptor antagonist in obese mice showed that this antagonist could improve the cardiometabolic risk in these mice without inhibition of the central CB1 receptor (Tam et al., 2010). Therefore, peripheral CB1 receptor antagonists might have therapeutic potential for improving metabolic risk in obese patients without causing psychiatric side effects.

Multidrug resistance-associated proteins (MRPs) are efflux transporters that can influence drug disposition by transporting a wide variety of substrates out of the cell (Zhou et al., 2008), preventing drugs from entering specific tissues or organs (e.g., intestine and brain), or increasing elimination of compounds, e.g., via liver and kidney (Yu et al., 2007). MRP1, MRP2, MRP3, and MRP4 belong to the ATP-binding cassette $(\mathrm{ABC})$ transporter subfamily $\mathrm{C}$ and have

ABBREVIATIONS: CB1, cannabinoid type 1; MRP, multidrug resistance-associated protein; ABC, ATP-binding cassette; $\mathrm{E}_{2} 17 \beta \mathrm{G}$, estradiol-17$\beta$-D-glucuronide; eYFP, enhanced yellow fluorescent protein; HEK, human embryonic kidney; E-64, $N$-(trans-epoxysuccinyl)-L-leucine 4-guanidinobutylamide; LC, liquid chromatography; MS/MS, tandem mass spectrometry; TFA, trifluoroacetic acid; CP55,940, 5-(1,1-dimethylheptyl)-2-[5hydroxy-2-(3-hydroxypropyl) cyclohexyl]phenol; E3040, 6-hydroxy-5,7-dimethyl-2-methylamino-4-(3-pyridylmethyl) benzothiazole. 
overlapping substrate specificities (Kruh and Belinsky, 2003). MRP1 is present in many tissues, with the highest protein expression in lung, adrenal gland, heart, and skeletal muscle, and lower amounts in brain, choroid plexus, spleen, kidney, intestine, testes, placenta, and liver (Flens et al., 1996; Rao et al., 1999; Nies et al., 2004; Leslie et al., 2005). It is expressed basolaterally in most tissues, but it has an apical localization in brain capillary endothelial cells (Nies et al., 2004; Leslie et al., 2005). MRP2 is highly expressed in liver, and lower expression levels can be found in the apical membranes of kidney tubules, gastrointestinal tract, gallbladder, placenta, and bronchi (van Aubel et al., 2000; Nies and Keppler, 2007). MRP3 is expressed in kidney, colon, small intestine, liver, and gallbladder, where it is found mostly in basolateral membranes (Scheffer et al., 2002). MRP4 is widely distributed in tissues and blood cells and has a dual membrane localization, which is basolateral in prostate tubuloacinar cells, hepatocytes, and choroid plexus, and apical in kidney proximal tubule cells and brain capillary endothelium (Nies et al., 2004; Russel et al., 2008). The expression of MRP1-4 at locations that are involved in drug disposition and penetration suggests that they influence drug concentrations in plasma and different organs, and because of their presence in the blood-brain-barrier and choroid plexus, MRP4 and MRP1 might play a role in restricting $\mathrm{CB} 1$ receptor antagonists from the brain.

Interaction of a drug with efflux transporters not only can influence its own pharmacokinetics, but it also can change the disposition of other compounds that are substrates for the same transporter. Studies describing the interaction of CB1 receptor antagonists with MRP1-4 may give information not only on the pharmacokinetics of these antagonists but also on possible drug-drug interactions. Here, we investigated the in vitro effect of a series of 3,4-diarylpyrazoline CB1 receptor antagonists (Fig. 1) (Lange et al., 2005) and the prototypic CB1 receptor antagonist rimonabant on MRP1-4 transport activity. In addition, for some 3,4-diarylpyrazolines, we related their transporter interaction to preliminary in vivo pharmacodynamic effects measured in rats.

\section{Materials and Methods}

Materials. $\left[6,7-{ }^{3} \mathrm{H}(N)\right]$ Estradiol $17-\beta$-D-glucuronide $(41.8 \mathrm{Ci} / \mathrm{mmol})$ was purchased from PerkinElmer Life and Analytical Sciences (Groningen, The Netherlands). Bac-to-Bac and Gateway systems, Dulbecco's modified Eagle's medium + GlutaMAX-I culture medium, and fetal calf serum were purchased from Invitrogen (Breda, The Netherlands). Triple flasks $\left(500 \mathrm{~cm}^{2}\right)$ were purchased from Sanbio BV Biological Products (Uden, The Netherlands). Estradiol $17-\beta$-D-glucuronide $\left(\mathrm{E}_{2} 17 \beta \mathrm{G}\right)$, adenosine 5 '-triphosphate magnesium salt (from bacterial source), and adenosine $5^{\prime}$-monophosphate monohydrate (from yeast) were purchased from Sigma-Aldrich (Zwijndrecht, The Netherlands). Protein concentrations were determined with a Bio-Rad protein assay kit from Bio-Rad Laboratories (Veenendaal, The Netherlands). Monoclonal mouse-anti-human MRP3 antibody M3II-21 was purchased from Abcam (Cambridge, UK). Monoclonal mouse-anti-human MRP1 (QCRL-1) was kindly provided by Dr. S. P. C. Cole (Queen's University Cancer Research Institute, Kingston, ON, Canada). 3,4-Diarylpyrazoline CB1 receptor antagonists (Lange et al., 2005) and rimonabant were kindly provided by Abbott Healthcare Products (Hannover, Germany).

Generation of Baculovirus. Full-length human MRP1, MRP2, and MRP3 were cloned separately into the Gateway pDONR221vector. The sequence of MRP1 was equal to GenBank accession number NM_004996 except for three silent mutations at base pairs 1684, 1704, and 4002, which are known polymorphisms (Conrad et al., 2001). The sequence of MRP2 was equal to
A

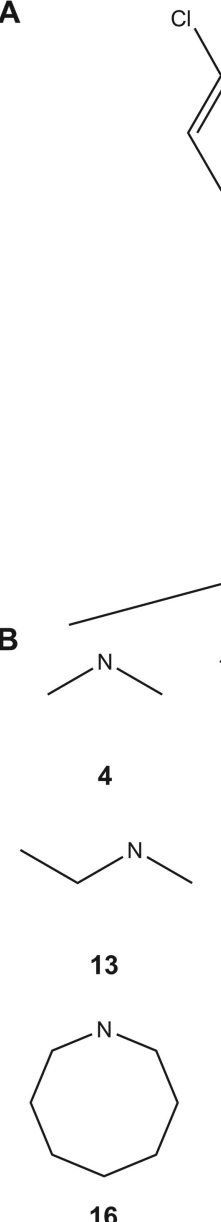

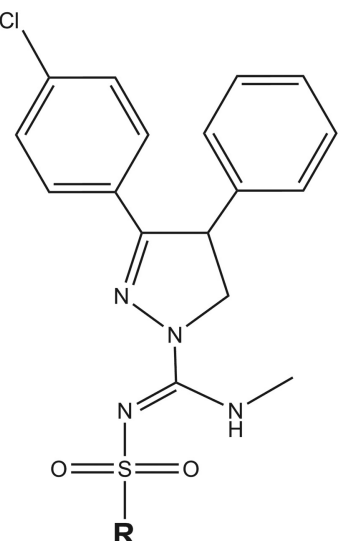

C

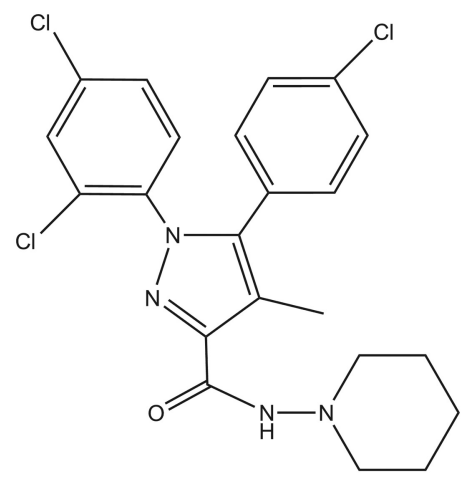

FIG. 1. Chemical structure of $\mathrm{CB} 1$ receptor antagonists. Core structure of 3,4-diarylpyrazoline derivatives 4, 11 to 17 , and 23 (A) with the chemical structures of $\mathbf{R}$ for the $N$-substituent of these compounds (B) (Lange et al., 2005). C, structure of rimonabant.

12<smiles>C1CCNC1</smiles><smiles>C1CCCNCC1</smiles><smiles>C1CSCCN1</smiles>

17<smiles>O=S1(=O)CCNCC1</smiles> 
NM_000392 except for three silent mutations at base pairs 264, 1167, and 3972, of which C3972T is a known polymorphism (Ito et al., 2001), and the sequence of MRP3 was equal to NM_003786. Consequently, constructs were also cloned into a VSV-G improved pFastBacDual vector for mammalian cell transduction using the Gateway system (El-Sheikh et al., 2007). Full-length human MRP4 and enhanced yellow fluorescent protein (eYFP), which was used as a negative control, were cloned previously (El-Sheikh et al., 2007). Baculoviruses were produced as described in the Bac-to-Bac manual (Invitrogen).

Cell Culture and Transduction of HEK293 Cells. HEK293 cells were grown in Dulbecco's modified Eagle's medium-GlutaMAX-I supplemented with $10 \%$ fetal calf serum at $37^{\circ} \mathrm{C}$ under $5 \% \mathrm{CO}_{2}$-humidified air. HEK293 cells were cultured in $500 \mathrm{~cm}^{2}$ triple flasks until $40 \%$ confluent, after which culture medium was removed and $25 \mathrm{ml}$ of medium and $10 \mathrm{ml}$ of eYFP, MRP1, MRP2, MRP3, or MRP4 baculovirus was added. Cells were incubated for $15 \mathrm{~min}$ at $37^{\circ} \mathrm{C}$, after which a further $40 \mathrm{ml}$ of medium was added, and 5 $\mathrm{mM}$ sodium butyrate was added $24 \mathrm{~h}$ after transduction. Three days after transduction, cells were harvested by centrifugation at $5000 \mathrm{~g}$ for $5 \mathrm{~min}$.

Isolation of Membrane Vesicles and Protein Analysis. Membranes were isolated according to a previously described method with slight modifications (El-Sheikh et al., 2008). In brief, harvested cell pellets were resuspended in ice-cold homogenization buffer $(0.5 \mathrm{mM}$ sodium phosphate and $0.1 \mathrm{mM}$ EDTA) supplemented with protease inhibitors (100 $\mu \mathrm{M}$ phenylmethylsulfonyl fluoride, $5 \mu \mathrm{g} / \mathrm{ml}$ aprotinin, $5 \mu \mathrm{g} / \mathrm{ml}$ leupeptin, $1 \mu \mathrm{g} / \mathrm{ml}$ pepstatin, and $1 \mu \mathrm{M}$ $N$-(trans-epoxysuccinyl)-L-leucine 4-guanidinobutylamide (E-64) and shaken at $4^{\circ} \mathrm{C}$ for $30 \mathrm{~min}$. Lysed cells were centrifuged at $100,000 \mathrm{~g}$ for $30 \mathrm{~min}$ at $4^{\circ} \mathrm{C}$, and the pellets were homogenized in ice-cold TS buffer (10 mM Tris-HEPES and $250 \mathrm{mM}$ sucrose, $\mathrm{pH}$ 7.4) supplemented with protease inhibitors described above, using a tight-fitting Dounce homogenizer for 25 strokes. After centrifugation at $1000 \mathrm{~g}$ for $20 \mathrm{~min}$ at $4^{\circ} \mathrm{C}$, the supernatant was centrifuged at $100,000 \mathrm{~g}$ for $60 \mathrm{~min}$ at $4^{\circ} \mathrm{C}$. The resulting pellet was resuspended in TS buffer without protease inhibitors and passed through a 27 -gauge needle 25 times. Protein concentration was determined by a Bio-Rad protein assay kit. Crude membrane vesicles were dispensed in aliquots, frozen in liquid nitrogen, and stored at $-80^{\circ} \mathrm{C}$ until further use.

Western Blotting. Membrane vesicle preparations were solubilized in SDS-polyacrylamide gel electrophoresis sample buffer and separated on SDS gel containing $7.5 \%$ acrylamide according to Laemmli. Then, they were blotted on nitrocellulose membrane using the iBlot dry blotting system (Invitrogen). Monoclonal mouse-anti-human MRP1 (QCRL-1, 1:700) and MRP3 (M3II-21, 1:200) antibodies and affinity-purified, polyclonal rabbit-anti-human MRP2 (polyclonal antibody hM2-p2, 1:500) and MRP4 (polyclonal antibody hM4-p4, 1:1000) (van Aubel et al., 2002; Smeets et al., 2004) were used to detect transporters. The secondary antibodies used in 1:10,000 dilution were fluorescent goat-anti-mouse IRdye800 (Rockland Immunochemicals, Gilbertsville, PA) and goat-anti-rabbit Alexa Fluor 680 (Invitrogen). Signals were visualized using the Odyssey imaging system (Li-Cor Biosciences, Lincoln, NE).

Vesicular Transport Assays. Uptake of $\left[{ }^{3} \mathrm{H}\right] \mathrm{E}_{2} 17 \beta \mathrm{G}$ into membrane vesicles was performed using a rapid filtration technique (van Aubel et al., 1999). The 30- $\mu$ l reaction mix consisted of TS buffer, $4 \mathrm{mM} \mathrm{ATP,} 10 \mathrm{mM} \mathrm{MgCl}_{2}$, $\mathrm{E}_{2} 17 \beta \mathrm{G}$, and $7.5 \mu \mathrm{g}$ of membrane vesicles; 0.1 (MRP1), 0.15 (MRP2, MRP4), and $0.2 \mu \mathrm{Ci}$ (MRP3) of $\left[{ }^{3} \mathrm{H}\right] \mathrm{E}_{2} 17 \beta \mathrm{G}$ was used, supplemented with unlabeled $\mathrm{E}_{2} 17 \beta \mathrm{G}$ to concentrations indicated in legends. The reaction was started when the mixture was incubated at $37^{\circ} \mathrm{C}$ and then stopped by placing samples on ice and adding $150 \mu \mathrm{l}$ of ice-cold TS buffer. A MultiScreen ${ }_{\mathrm{HTS}}-\mathrm{HV}, 0.45-\mu \mathrm{m}$, polyvinylidene difluoride 96-well filter plate was prewashed with TS buffer, and diluted samples were filtered through this filter plate using a MultiScreen $_{\text {HTS }}$ vacuum manifold filtration device (Millipore, Etten-Leur, The Netherlands). The filters were washed twice with TS buffer and were then separated from the plate. After addition of $2 \mathrm{ml}$ of scintillation fluid to each filter and subsequent liquid scintillation counting, uptake of $\left[{ }^{3} \mathrm{H}\right] \mathrm{E}_{2} 17 \beta \mathrm{G}$ into membrane vesicles was determined by measuring radioactivity associated with the filters. In control experiments, ATP was substituted with AMP. Net ATP-dependent transport was calculated by subtracting values measured in the presence of AMP from those measured in the presence of ATP. Timedependent transport was found to be linear up to $5 \mathrm{~min}$ for MRP1, MRP2, and MRP4 and up to 3 min for MRP3 (results not shown).
Vesicular Interaction Assays. To evaluate the inhibitory effects of 3,4diarylpyrazolines and rimonabant on $\left[{ }^{3} \mathrm{H}\right] \mathrm{E}_{2} 17 \beta \mathrm{G}$ uptake in MRP1, 2, 3, and 4 inside-out membrane vesicles, the above-mentioned transport assay was performed in the absence or presence of 10 and $100 \mu \mathrm{M}$ CB1 receptor antagonists. The concentration-dependent effect of 1 to $100 \mu \mathrm{M}$ concentrations of compounds 13,15 , and rimonabant was measured at three different $\mathrm{E}_{2} 17 \beta \mathrm{G}$ concentrations: $0.16,1$, and $5 \mu \mathrm{M}$ for MRP1; 2, 20, and $200 \mu \mathrm{M}$ for MRP2; $0.08,1$, and $5 \mu \mathrm{M}$ for MRP3; and $0.1,0.3$, and $1 \mu \mathrm{M}$ for MRP4. ATPdependent transport was calculated.

Determination of Actual Concentrations of 3,4-Diarylpyrazolines and Rimonabant with LC-MS/MS. The actual amount of CB1 receptor antagonists dissolved under vesicular transport assay conditions was measured. eYFP vesicles $(7.5 \mu \mathrm{g})$ were added in each well to mimic the vesicle environment. The reaction mixture without $\left[{ }^{3} \mathrm{H}\right] \mathrm{E}_{2} 17 \beta \mathrm{G}$ was added on ice and only the AMP condition was measured. The 96-well plate was mixed, and the total reaction mixture from one well was transferred to an Eppendorf tube at room temperature. Sample was spun down at maximal speed $(16,000-20,000 g)$ for 5 min at room temperature and $10 \mu \mathrm{l}$ of supernatant was reconstituted in 50\% acetonitrile-water and $0.1 \%$ trifluoroacetic acid (TFA) before LC-MS/MS analysis. Actual concentrations were determined using an Accela ultrahighperformance liquid chromatograph (Thermo Fisher Scientific, Waltham, MA) coupled to a TSQ Vantage (Thermo Fisher Scientific) triple quadrupole mass spectrometer. The $\mathrm{CB} 1$ receptor antagonists were separated on a Zorbax Eclipse Plus column $(50 \times 2.1 \mathrm{~mm}, 1.8-\mu \mathrm{m}$ particle size; Agilent Technologies, Santa Clara, CA). The elution gradient was as follows: 0 min, $50 \%$ B; 5 $\min , 90 \% \mathrm{~B}$; and $6 \mathrm{~min}, 50 \% \mathrm{~B}$. Solvent A consisted of $0.1 \%$ TFA in ultrapure water, and solvent $\mathrm{B}$ consisted of $0.1 \% \mathrm{TFA}$ in acetonitrile. The column temperature was set at $40^{\circ} \mathrm{C}$, and the flow rate was $200 \mu \mathrm{l} / \mathrm{min}$. The effluent from the high-performance liquid chromatograph was passed directly into the electrospray ion source. Positive electrospray ionization was achieved using a nitrogen sheath gas with ionization voltage at $4 \mathrm{kV}$. The capillary temperature was set at $350^{\circ} \mathrm{C}$. Detection of each analyte was based on isolation of the protonated molecular ion, $[\mathrm{M}+\mathrm{H}]^{+}$, and subsequent MS/MS fragmentations and selected reaction monitoring were performed. The conditions per compound are summarized in Table 1. CB1 receptor antagonist 4 or 16 was used as an internal standard, and the response ratio of test compound to internal standard was used to determine the concentration. The actual assay concentration of compound was measured in duplicate in at least three independent experiments.

In Vivo Pharmacodynamic Effect of 3,4-Diarylpyrazolines on CP55,940Induced Hypotension in Rat. The $\mathrm{ED}_{50}$ of 3,4-diarylpyrazolines for attenuation of 5-(1,1-dimethylheptyl)-2-[5-hydroxy-2-(3-hydroxypropyl)cyclohexyl] phenol (CP55,940)-induced hypotension in male, normotensive, anesthetized Wistar rats was determined according to a method described previously using different intravenous doses ( $n=2$ per dose) of CB1 receptor antagonists 10 min before CP55,940 (0.1 mg/kg i.v.) administration (Lange et al., 2004). Hypotension was achieved within $1 \mathrm{~min}$ after administration of the CB1 receptor agonist CP55,940, and the lowest blood pressure was the measure of the hypotensive effect. $\mathrm{ED}_{50}$ was calculated on the linear part of the percentage dose-response curve and is the dose of antagonist that inhibited the hypotensive effect of CP55,940 by 50\%. Experiments

TABLE 1

LC-MS/MS conditions for detection of CB1 receptor antagonists

\begin{tabular}{|c|c|c|c|c|c|}
\hline \multirow{2}{*}{ Compound } & \multirow{2}{*}{$\begin{array}{l}\text { Retention } \\
\text { Time }\end{array}$} & \multirow{2}{*}{$\begin{array}{l}\text { Parent } \\
(m / z)\end{array}$} & \multicolumn{2}{|c|}{ Collision Energy $(\mathrm{m} / \mathrm{z})$} & \multirow{2}{*}{ S Lens } \\
\hline & & & Product 1 & Product 2 & \\
\hline & $\min$ & \multicolumn{4}{|c|}{$e V$} \\
\hline 4 & 3.2 & 420.182 & $255.060(27)$ & $375.140(13)$ & 115 \\
\hline 11 & 4.2 & 448.222 & $255.100(26)$ & $375.080(16)$ & 108 \\
\hline 12 & 4.2 & 448.221 & $255.060(30)$ & $375.050(14)$ & 111 \\
\hline 13 & 3.8 & 434.204 & $255.060(26)$ & $375.090(14)$ & 109 \\
\hline 14 & 3.5 & 446.205 & $255.090(28)$ & $375.100(16)$ & 118 \\
\hline 15 & 4.8 & 474.245 & $255.070(29)$ & $375.100(28)$ & 127 \\
\hline 16 & 5.4 & 488.261 & $255.060(31)$ & $375.090(19)$ & 130 \\
\hline 17 & 4.0 & 478.184 & $255.050(28)$ & $375.000(15)$ & 113 \\
\hline 23 & 2.6 & 510.169 & $255.080(29)$ & $375.100(15)$ & 127 \\
\hline Rimonabant & 3.2 & 463.163 & $299.000(46)$ & $363.020(29)$ & 125 \\
\hline
\end{tabular}


were approved by the local ethics committee on animal experimentation at Solvay Pharmaceuticals (Weesp, The Netherlands).

Kinetic Analysis. All data are expressed as means \pm S.E.M. Curve-fitting of the resulting concentration-dependent transport curves and determination of $\mathrm{IC}_{50}$ values for the $\mathrm{CB} 1$ receptor antagonists was performed by nonlinear regression analysis using GraphPad Prism software (version 5.02; GraphPad Software Inc., San Diego, CA). The following equation was fitted to the data: $y=$ bottom $+($ top - bottom $) /\left(1+10^{\left(\log \mathrm{IC}_{50}-x\right)} \cdot\right.$ Hill slope $)$, in which $x$ is the log inhibitor concentration and $y$ is expressed as uptake versus control (percentage). A Michaelis-Menten fit was used for MRP1, MRP3, and MRP4 E $217 \beta G$ curves, and an allosteric sigmoidal fit was used for MRP2. Log (inhibitor or stimulator) versus response with variable slope was used to plot the inhibition and stimulation curves with 13, 15, or rimonabant. Results of the inhibition assay for interaction of MRP1/4 with 13 and rimonabant were analyzed using Dixon's method combined with linear regression analysis to estimate the inhibitory constant $\left(K_{\mathrm{i}}\right)$. Statistical differences were determined using one-way analysis of variance with Dunnett's multiple comparison test in GraphPad Prism. Differences were considered to be significant at $p<0.05$.

\section{Results}

Expression of MRP1, MRP2, MRP3, and MRP4 in Isolated Membrane Vesicles. Immunoblot analysis performed on membrane vesicles from HEK293 cells overexpressing MRP1, MRP2, MRP3, and MRP4 demonstrated that all four transporters were successfully expressed (data not shown). MRP1 seemed to be less glycosylated as indicated by a band at $\sim 160 \mathrm{kDa}$, but this had no influence on its transport activity (Fig. 2A). The negative control, consisting of membrane vesicles from eYFP-overexpressing HEK293 cells, showed no expression of MRP1-4.

Concentration-Dependent Transport of $E_{2} 17 \beta G$ into MRP1-, MRP2-, MRP3-, and MRP4-Overexpressing Membrane Vesicles. Concentration-dependent uptake of $\mathrm{E}_{2} 17 \beta \mathrm{G}$ into membrane vesicles was measured after $5 \mathrm{~min}$ for all transporters, and typical curves are shown in Fig. 2, A to D. ATP-dependent $\mathrm{E}_{2} 17 \beta \mathrm{G}$ transport reached maximal activities $\left(V_{\max }\right)$ of $31 \pm 1,2220 \pm 100$, and $94 \pm 5$ pmol $\cdot$ $\mathrm{mg}^{-1} \cdot \min ^{-1}$ for MRP1, MRP3, and MRP4, respectively. The affinity of $\mathrm{E}_{2} 17 \beta \mathrm{G}\left(K_{\mathrm{m}}\right)$ for MRP1, MRP3, and MRP4 was $7.5 \pm 0.1$,
$56 \pm 6$, and $15 \pm 3 \mu \mathrm{M}$, respectively. Repetition of the experiment for each transporter gave comparable kinetic parameters; only the $V_{\max }$ of MRP3 varied between different batches of membrane vesicles, because of different expression levels of the transporter. Transport activity of MRP2 followed a sigmoidal relationship with increased $E_{2} 17 \beta G$ concentration (Fig. 2B). A Hill slope of $1.6 \pm 0.03$ was calculated for MRP2 activity, which is indicative of positive cooperativity.

Effects of 3,4-Diarylpyrazolines and Rimonabant on MRP1-, MRP2-, MRP3-, and MRP4-Mediated E 17 17G Transport. Based on the kinetics of $E_{2} 17 \beta G$ uptake by MRP1-4, the following $E_{2} 17 \beta G$ concentrations, well below the $K_{\mathrm{m}}$, were chosen for interaction studies with 3,4-diarylpyrazolines and rimonabant (Fig. 1): $0.16 \mu \mathrm{M}$ for MRP1, $20 \mu \mathrm{M}$ for MRP2, $0.08 \mu \mathrm{M}$ for MRP3, and $0.12 \mu \mathrm{M}$ for MRP4. In the case of MRP2, $20 \mu \mathrm{M}$ substrate was used to measure both stimulation and inhibition.

Figure 3 shows the effect of 10 and $100 \mu \mathrm{M}$ concentrations of the $\mathrm{CB} 1$ receptor antagonists on $\mathrm{E}_{2} 17 \beta \mathrm{G}$ transport by MRP1-4. Because of poor solubility, the actual concentrations of the 3,4-diarylpyrazolines and rimonabant were 3- to 100 -fold lower than the predicted concentrations (see legend to Fig. 3). The highest concentration of the series of 3, 4-diarylpyrazolines inhibited MRP4 transport activity (Fig. 3D) more potently than MRP1 activity (Fig. 3A). Of the 3,4-diarylpyrazolines, compounds 4 and 12 to 14 significantly inhibited MRP1- and MRP4mediated $\mathrm{E}_{2} 17 \beta \mathrm{G}$ transport. Compound 13 had the highest inhibitory effect on both transporters, with $-34 \pm 13$ and $-72 \pm 8 \%$ for MRP1 and MRP4, respectively. Transport of $\mathrm{E}_{2} 17 \beta \mathrm{G}$ by MRP1 and MRP4 was not inhibited by compounds 15 to 17 and 23, whereas compound $11 \mathrm{did}$ inhibit MRP4, but not MRP1. Rimonabant inhibited MRP1 more potently than MRP4, viz. $-84 \pm 4$ versus $-58 \pm 3 \%$ (Fig. 3, A and D). In contrast to MRP1 and MRP4, MRP2 transport activity was stimulated by most compounds at both concentrations tested (Fig. 3B). At the lower concentration, compounds 15 to 17 significantly increased uptake of $\mathrm{E}_{2} 17 \beta \mathrm{G}$ into MRP2 vesicles (256-305\%). Stimulation of MRP2 was strongest at the high concentration of compounds 4 to 14 (543-734\%) and less by compounds 15 to $17(349-412 \%)$ and rimonabant (513\%).
A

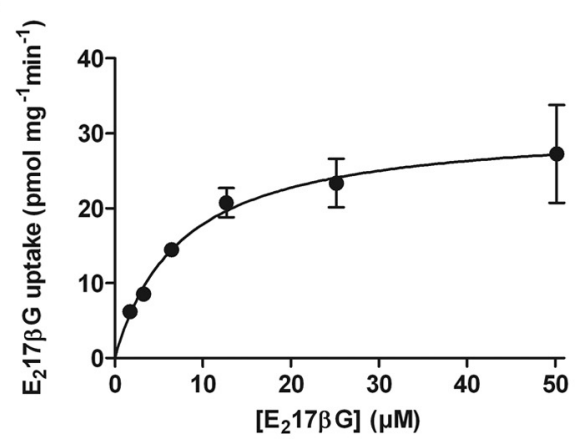

C

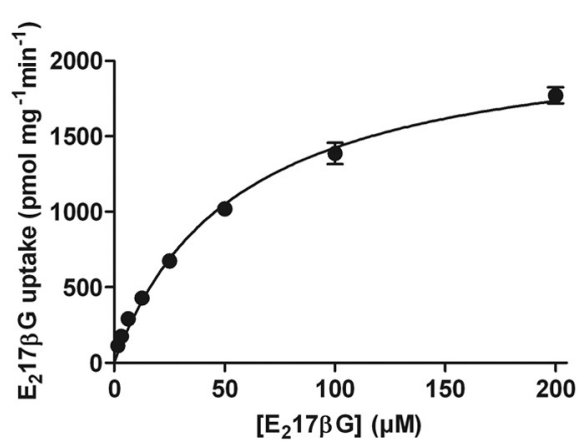

B

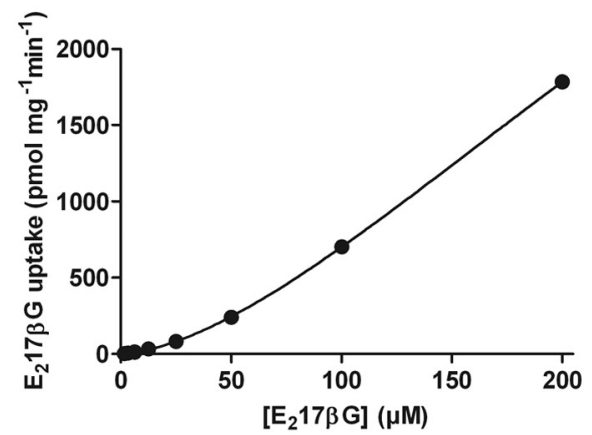

D

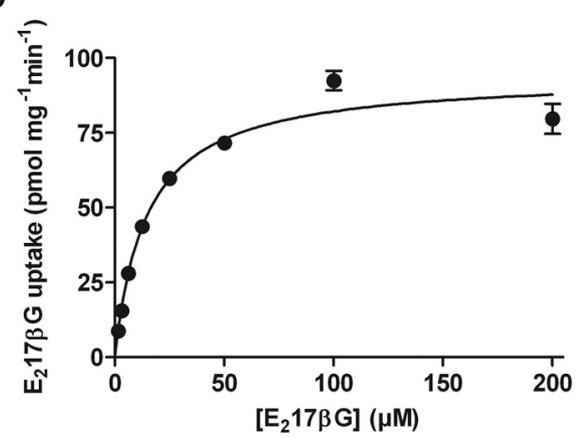

FIG. 2. Kinetics of ATP-dependent $\mathrm{E}_{2} 17 \beta \mathrm{G}$ transport into membrane vesicles of HEK293 cells overexpressing MRP1 (A), MRP2 (B), MRP3 (C), or MRP4 (D). Concentration-dependent $\mathrm{E}_{2} 17 \beta \mathrm{G}$ transport was determined after 5 min for all transporters. ATP-dependent eYFP values were subtracted from corresponding ATP-dependent MRP values, and $K_{\mathrm{m}}$ and $V_{\max }$ were determined by nonlinear regression analysis. Data points represent the mean \pm S.E.M. of triplicate measurements in a representative experiment. 

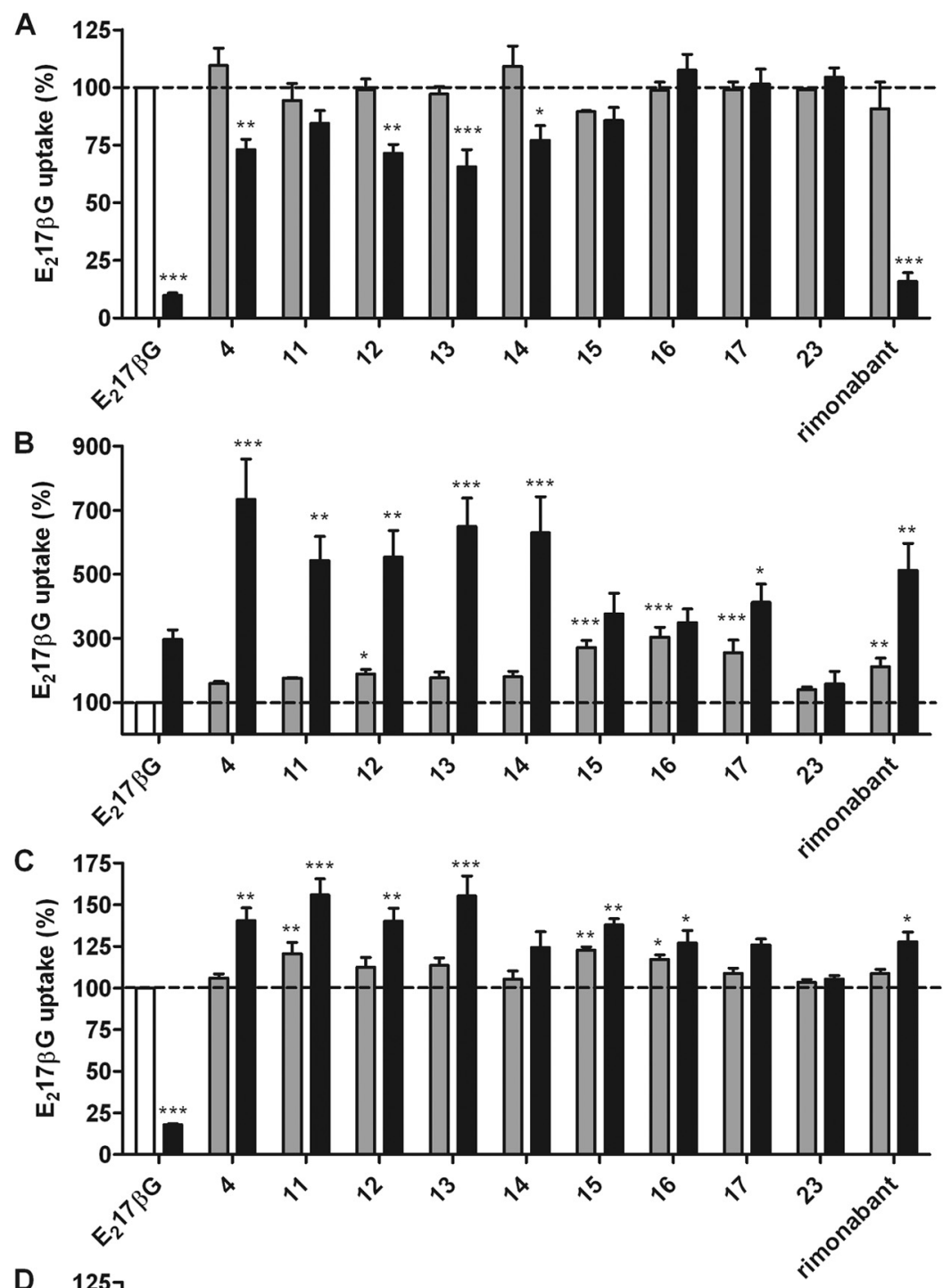

FIG. 3. Effect of $\mathrm{CB} 1$ receptor antagonists on ATP-dependent transport of $\mathrm{E}_{2} 17 \beta \mathrm{G}$ into MRP1- (A), MRP2- (B), MRP3- (C), or MRP4-overexpressing (D) membrane vesicles. Transport was measured during $5 \mathrm{~min}$ at concentrations of $0.16,20,0.08$, and $0.12 \mu \mathrm{M}$ $\mathrm{E}_{2} 17 \beta \mathrm{G}$, for MRP1, MRP2, MRP3, and MRP4, respectively, in the absence $(\square)$ or presence of CB1 receptor antagonists. Because of their poor solubility, concentrations in the low range varied between 0.4 and $2.2 \mu \mathrm{M}$ (圈) and between 4 and $33 \mu \mathrm{M}$ (ם) for the 10-fold higher range. Actual concentrations of $\mathrm{CB} 1$ receptor antagonists corresponding to the gray bars were $2.2 \mu \mathrm{M}$ for compound $4,0.7$ to $1.3 \mu \mathrm{M}$ for compounds 11 to 17 and 23 , and $0.4 \mu \mathrm{M}$ for rimonabant. Actual concentrations corresponding to the black bars were $33 \mu \mathrm{M}$ for $\mathrm{CB} 1$ receptor antagonist $4,7 \mu \mathrm{M}$ for compounds 11 and $12,12 \mu \mathrm{M}$ for compounds 13 and 14,1 to $3 \mu \mathrm{M}$ for compounds 15 to 17 and 23 , and $4 \mu \mathrm{M}$ for rimonabant. ATP-dependent uptake in the absence of CB1 receptor antagonists was set at $100 \%(\square)$ and was also measured in the presence of $100 \mu \mathrm{M} \mathrm{E}_{2} 17 \beta \mathrm{G}$ ( $\square$ ). Means \pm S.E.M. of three independent experiments are shown. Statistically significant differences from vehicle control: $*, p<$ $0.05 ; * *, p<0.01 ; * * *, p<0.001$

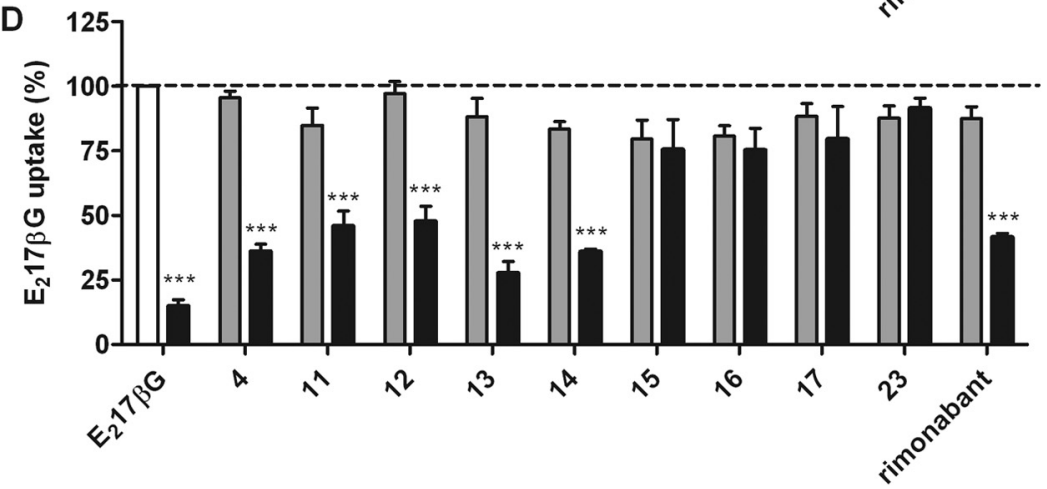

Compound 23 did not significantly increase transport. Figure 3C shows that, although $\mathrm{E}_{2} 17 \beta \mathrm{G}$ itself inhibited transport, MRP3-mediated $\mathrm{E}_{2} 17 \beta \mathrm{G}$ transport was significantly stimulated by rimonabant and most 3,4-diarylpyrazolines, of which compounds 11 and 13 had the highest stimulatory effect $(\sim 155 \%)$.

Mechanism of Modulation of MRP1-4 Transport by Compounds 13, 15, and Rimonabant. To get a better understanding of the mechanism of interaction, we measured concentration-dependent effects of certain CB1 receptor antagonists on MRP1-4 transport at three different $\mathrm{E}_{2} 17 \beta \mathrm{G}$ concentrations for each transporter (Fig. 4). 3,4-Diarylpyrazoline derivatives 13 and 15 and rimonabant were selected for further investigation because the magnitude of their effects on the transport activity were different.

Increasing $\mathrm{E}_{2} 17 \beta \mathrm{G}$ concentrations did not decrease the potency of 3,4-diarylpyrazolines 13 and 15 and rimonabant for inhibiting MRP1 and MRP4 (Fig. 4, A-C and J-L); the percentage of inhibition and the $\mathrm{IC}_{50}$ values of 13 and rimonabant for MRP4 and MRP1 were similar at different $\mathrm{E}_{2} 17 \beta \mathrm{G}$ concentrations. Dixon plots for 13- and rimonabant-mediated inhibition of MRP4 and MRP1 show that the lines intersected virtually at the $x$-axis for both compounds, which is indicative of noncompetitive inhibition (Fig. 5, A-C). The intersections corresponded to a $K_{\mathrm{i}}$ of $\sim 1.4 \mu \mathrm{M}$ rimonabant for MRP1, $\sim 4$ 
A

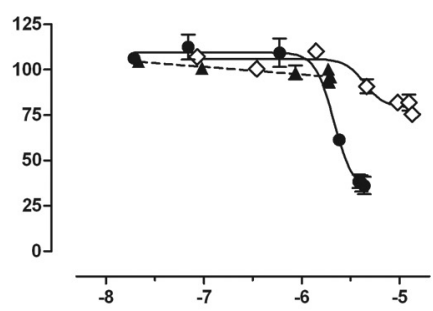

D

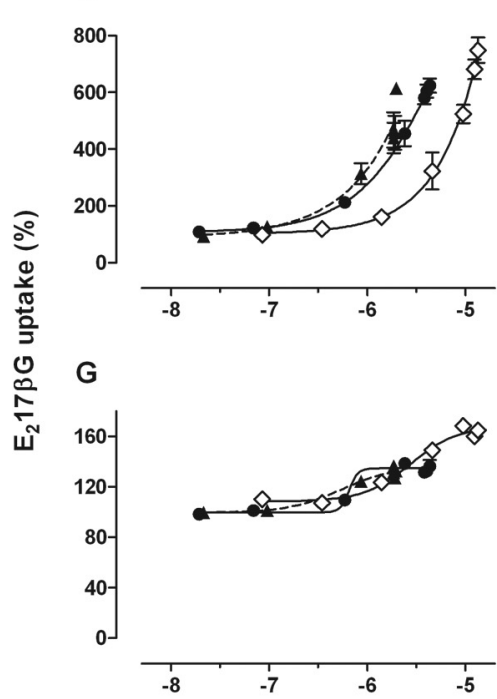

$\mathrm{J}$

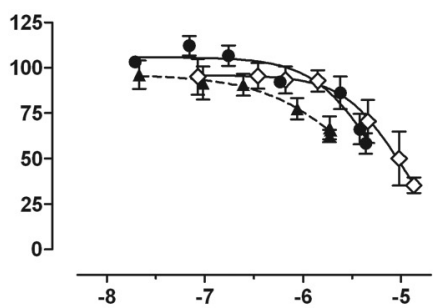

B

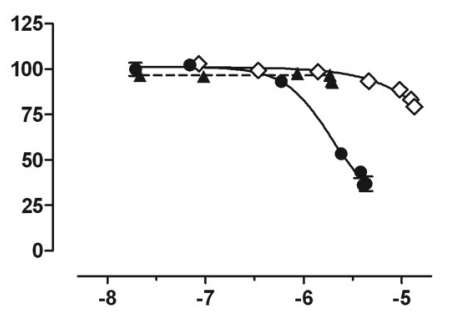

E

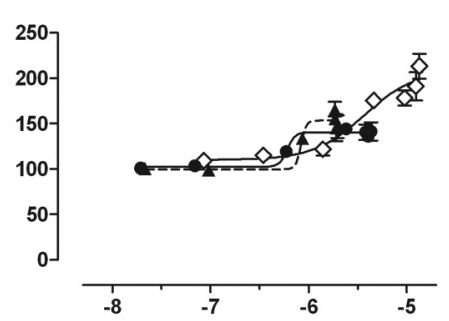

H

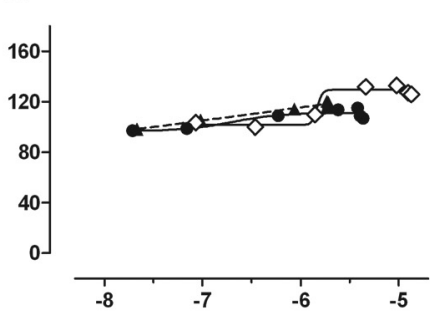

K

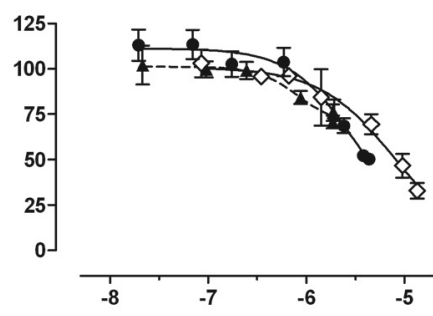

C

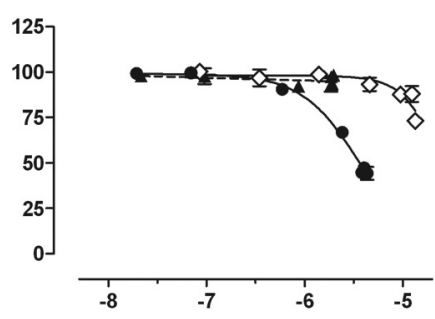

F

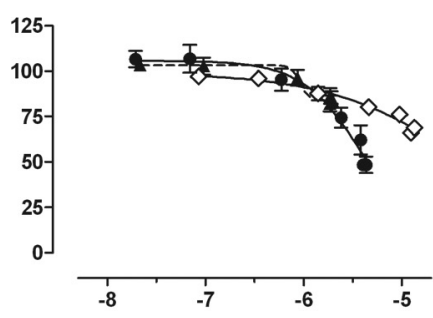

I

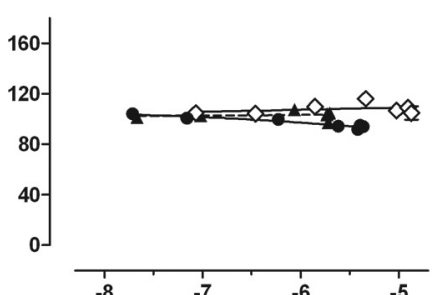

L

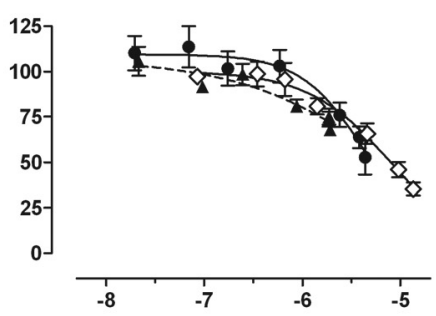

$\log$ [CB1 antagonist] (M)

$\mu \mathrm{M}$ rimonabant for MRP4, and $\sim 7 \mu \mathrm{M} 13$ for MRP4. 3,4Diarylpyrazoline 15 did not inhibit MRP1 transport activity at any of the concentrations tested and only moderately inhibited MRP4 (Fig. 4, A-C and $\mathrm{J}-\mathrm{L}$ ).

MRP2-mediated transport was stimulated by compounds 13, 15, and rimonabant at the lowest $\mathrm{E}_{2} 17 \beta \mathrm{G}$ concentration of $2 \mu \mathrm{M}$ (Fig. 4D). Stimulation was decreased at $20 \mu \mathrm{M} \mathrm{E}_{2} 17 \beta \mathrm{G}$, and transport was inhibited at $200 \mu \mathrm{M} \mathrm{E} \mathrm{E}_{2} 17 \beta \mathrm{G}$ (Fig. 4, D-F). Rimonabant and compound 15 appeared to have the same stimulatory and inhibitory potency on MRP2-mediated transport.

MRP3-mediated $E_{2} 17 \beta G$ transport was stimulated at a low substrate concentration, which gradually disappeared at higher substrate concentrations (Fig. 4, G-I). At a concentration of $15 \mu \mathrm{M} \mathrm{E} \mathrm{E}_{2} 17 \beta \mathrm{G}$, high concentrations of compounds 13 and 15 and rimonabant inhibited $\mathrm{E}_{2} 17 \beta \mathrm{G}$ transport via MRP3 (data not shown).
In Vivo Pharmacodynamic Effect of 3,4-Diarylpyrazolines on CP55,940-Induced Hypotension in Rat. To get an impression of the relative brain penetration of the 3,4-diarylpyrazolines, the $\mathrm{CB} 1$ receptor-mediated blood pressure effect of compounds $4,11,14$, and 15 was compared with their in vitro $\mathrm{CB} 1$ receptor binding affinity. For this purpose, in rats, we measured the initial rapid effect of $\mathrm{CB} 1$ receptor antagonists on CP55,940-induced hypotension, which is considered to originate primarily from a central sympathetic response (Vollmer et al., 1974). Table 2 describes the effective intravenous dose $\left(\mathrm{ED}_{50}\right)$ that was needed for $50 \%$ inhibition of the hypotensive effect of CP55,940 and the binding affinity (expressed as $K_{\mathrm{i}}$ ) of these compounds for the $\mathrm{CB} 1$ receptor, as determined previously (Lange et al., 2005). The in vivo data show that CB1 receptor antagonist 15 had the lowest $\mathrm{ED}_{50}$ value. If the $\mathrm{ED}_{50}$ of 15 relative to its binding affinity is extrapolated to compounds 4,11 , and 14 on basis of their $K_{\mathrm{i}}$ values for 

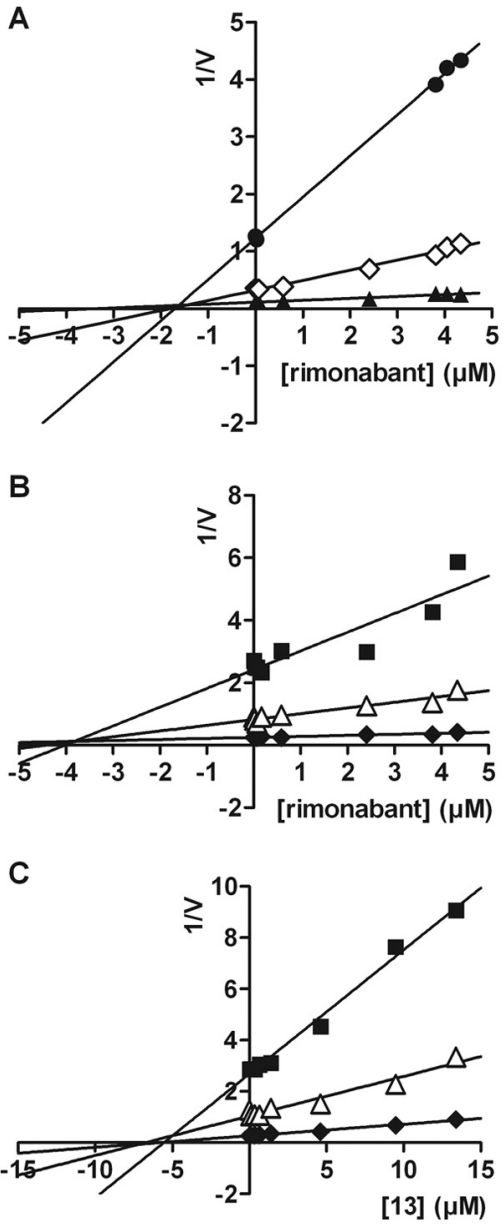

FIG. 5. Dixon plots of inhibition of MRP1- and MRP4-mediated ATP-dependent $\mathrm{E}_{2} 17 \beta \mathrm{G}$ transport by rimonabant and 3,4-diarylpyrazoline 13 . The reciprocal of transport velocity $(1 / V)$ of different substrate concentrations is plotted against the inhibitor concentration. Dixon plots of inhibition of MRP1 (A) and MRP4 (B) by rimonabant and of MRP4 by compound $13(\mathrm{C})$ at three different $\mathrm{E}_{2} 17 \beta \mathrm{G}$ concentrations are shown $\left[0.16 \mu \mathrm{M}(\boldsymbol{\bullet}), 1 \mu \mathrm{M}(\diamond)\right.$, and $5 \mu \mathrm{M}(\boldsymbol{\Delta}) \mathrm{E}_{2} 17 \beta \mathrm{G}$ MRP1 for MRP1 and $0.1 \mu \mathrm{M}(\square), 0.3 \mu \mathrm{M}(\triangle)$, and $1 \mu \mathrm{M}(\diamond) \mathrm{E}_{2} 17 \beta \mathrm{G}$ for MRP4]. Linear regression analysis was used for plotting lines and determination of $K_{\mathrm{i}}$. Data represent the mean $1 / \mathrm{V}$ of duplicate measurements in a representative experiment.

the $\mathrm{CB} 1$ receptor, $\mathrm{ED}_{50}$ values of $0.14,0.02$, and $0.15 \mathrm{mg} / \mathrm{kg}$, respectively, would have been expected. However, the actual $\mathrm{ED}_{50}$ values of compounds 4,11 , and 14 (Table 2 ) were $>2, \sim 10$, and $\sim 4.7$ times higher than expected, indicating a lower brain permeability compared with that for compound 15 .

\section{Discussion}

This study shows that $\mathrm{CB} 1$ receptor antagonists interacted with the efflux transporters MRP1, MRP2, MRP3, and MRP4. $\mathrm{E}_{2} 17 \beta \mathrm{G}$ was used as a model substrate to investigate the effect of $\mathrm{CB} 1$ receptor antagonists on transport activity of these transporters. The kinetic parameters for $\mathrm{E}_{2} 17 \beta \mathrm{G}$ found in this study were comparable to those in the literature (Loe et al., 1996; Zeng et al., 2000; Chen et al., 2001). Unlike MRP1, MRP3, and MRP4, MRP2 transported $\mathrm{E}_{2} 17 \beta \mathrm{G}$ in a positive cooperative manner, which was previously demonstrated by others (Bodó et al., 2003a; Zelcer et al., 2003).

Actual tested concentrations of the very lipophilic CB1 receptor antagonists in the experimental assays were determined by LCMS/MS and were 3- to 100-fold lower than expected. This result may be due to incomplete dissolution or nonspecific binding. In our study, compounds 15 to 17 stimulated MRP2 better than compounds 4 to 14 at low concentrations. In contrast, the opposite was found at higher concentrations, at which the actual concentrations of compounds 15 to 17 were lower $(1-3 \mu \mathrm{M})$ than those of 4 to $14(7-33 \mu \mathrm{M})$ (Fig. 3). This result indicates that compounds 15 to 17 , which contain $\mathrm{N}$ substituents that make them more lipophilic, have a higher potency in affecting MRP2 but have a limited effect because of their low solubility. The same was found for MRP3, and the lack of effect of compounds 15 to 23 on MRP1 and MRP4 might also be explained by their low actual concentrations.

Although we used $\mathrm{E}_{2} 17 \beta \mathrm{G}$ as a substrate for all transporters, the effect of the $\mathrm{CB} 1$ receptor antagonists on transport of this substrate via MRP1-4 was different. MRP1- and MRP4-mediated transport was inhibited by several CB1 receptor antagonists. The inhibitory affinity of rimonabant was somewhat higher for MRP1-mediated $\mathrm{E}_{2} 17 \beta \mathrm{G}$ transport than for MRP4-mediated transport, with a $K_{\mathrm{i}}$ of $\sim 1.4 \mu \mathrm{M}$ versus $\sim 4 \mu \mathrm{M}$. The maximal plasma concentration found in male human subjects treated with a therapeutic dose of rimonabant is 0.4 $\mu \mathrm{M}$ (Turpault et al., 2006). Rimonabant and 3,4-diarylpyrazoline 13 appeared to inhibit MRP1 and MRP4 in a noncompetitive manner (Fig. 5, A-C). In addition, MRP1 and MRP4 were stimulated at low substrate and rimonabant concentrations, indicating that rimonabant probably does not compete for the $\mathrm{E}_{2} 17 \beta \mathrm{G}$ binding site of either transporter (Fig. 4, A and J). Whether rimonabant and the 3,4diarylpyrazolines are only inhibitors or are also substrates of MRP1 or MRP4 cannot be concluded from this study.

In contrast to MRP1 and MRP4, MRP2-mediated transport was stimulated by all CB1 receptor antagonists, except for compound 23. The results presented in this study suggest that 3,4-diarylpyrazolines and rimonabant stimulate MRP2 allosterically at low $\mathrm{E}_{2} 17 \beta \mathrm{G}$ concentrations and compete for the $\mathrm{E}_{2} 17 \beta \mathrm{G}$ binding site at high concentrations. This type of interaction is supported by other studies (Bakos et al., 2000; Evers et al., 2000; Zelcer et al., 2003). The study of Zelcer et al. (2003) showed that several aromatic compounds, most of them containing sulfoxide or tosyl groups, stimulate MRP2-mediated transport of $\mathrm{E}_{2} 17 \beta \mathrm{G}$ into membrane vesicles. Compounds that normalized the stimulated transport rates at increasing concentrations, such as sulfinpyrazone and indomethacin, also appeared to be substrates for MRP2 (Evers et al., 2000; Zelcer et al., 2003). 3,4-Diarylpyrazolines chemically resemble sulfinpyrazone, which, together with the fact that compounds 13 and 15 and rimonabant might compete with $E_{2} 17 \beta G$ at higher substrate concentrations, could indicate that they are substrates for MRP2.

The CB1 receptor antagonists had comparable effects on MRP3 transport activity, but their effects were less pronounced than those for MRP2 (Fig. 4, G-I). Other studies reported that MRP3-mediated $\mathrm{E}_{2} 17 \beta \mathrm{G}$ transport activity can be inhibited as well as stimulated by different compounds, e.g., 6-hydroxy-5,7-dimethyl-2-methylamino-4(3-pyridylmethyl) benzothiazole (E3040) sulfate, indomethacin, and benzbromarone (Akita et al., 2002; Bodó et al., 2003a,b). This result indicates that the 3,4-diarylpyrazolines and rimonabant would interact

TABLE 2

Pharmacodynamic characteristics of the CB1 receptor antagonists

\begin{tabular}{rcc}
\hline Compound & $\mathrm{CB} 1_{\mathrm{rb}}\left(K_{\mathrm{i}}\right)^{a}$ & $\mathrm{ED}_{50}{ }^{b}$ \\
\hline & $n M$ & $m g / k g$ i.v. \\
4 & $223 \pm 103$ & $>0.3$ \\
11 & $30 \pm 14$ & 0.2 \\
15 & $231 \pm 66$ & 0.7 \\
& $155 \pm 69$ & 0.1 \\
\hline
\end{tabular}

${ }^{a} \mathrm{CB} 1_{\mathrm{rb}}$, displacement of specific $\mathrm{CP} 55,940$ binding in $\mathrm{CHO}$ cells stably transfected with human CB1 receptor, expressed as $K_{\mathrm{i}} \pm$ S.E.M. Data were adapted from Lange et al. (2005).

${ }^{b}$ Dose of CB1 receptor antagonist that attenuates CP55,940-induced hypotension in rats $(n=$ $2 /$ dose) by $50 \%$. 
with a modulating site and the substrate site of MRP3, causing stimulation of $\mathrm{E}_{2} 17 \beta \mathrm{G}$ transport at low substrate concentrations and inhibition at higher substrate concentrations because of competition for the substrate site.

Our results show that rimonabant and 3,4-diarylpyrazolines can modulate MRP1-4 transport activity, which implies the possibility of drug-drug interactions. Because of the brief clinical use of rimonabant, few data are available on its in vivo interaction potential with drug transporters. Rimonabant was found to moderately affect the pharmacokinetics of the P-glycoprotein (ABCB1) substrate cyclosporine, but not of tacrolimus and digoxin (Kanamaluru et al., 2005; Amundsen et al., 2009).

The pharmacokinetic data available for rimonabant do not suggest an important role for the MRPs in determining its disposition. Rimonabant is shown to accumulate in fat tissue, spleen, thyroid, thymus, liver, plasma, and brain and is reported to cross the placental barrier (Barna et al., 2009) (European Medicines Agency-European Public Assessment Reports scientific discussion about rimonabant, http:// www.ema.europa.eu/docs/en_GB/document_library/EPAR_-_ Scientific_Discussion/human/000666/WC500021284.pdf). Although rimonabant showed a strong interaction with MRP1, its accumulation in the brain and passage across the placental barrier indicates that it is either a poor substrate of this transporter, or MRP1 is not efficacious enough as a barrier for rimonabant.

MRP1 and MRP4 are expressed at the blood-brain-barrier and the choroid plexus, where these transporters could be involved in limiting the brain penetration of the 3,4-diarylpyrazoline CB1 receptor antagonists. Because there are only minor differences in the structures of the 3,4-diarylpyrazolines, the rate and extent of passive diffusion of these compounds into the brain and other tissues is expected to be similar, which should reflect in a similar relationship between $\mathrm{ED}_{50}$ and $\mathrm{CB} 1$ receptor binding affinity $\left(K_{\mathrm{i}}\right)$. However, there was a difference in $\mathrm{ED}_{50}$ values for compounds $4,11,14$, and 15 , which could not solely be attributed to differences in $\mathrm{CB} 1$ receptor binding affinities. The $\mathrm{ED}_{50}$ values of compounds 4,11 , and 14 relative to their $K_{\mathrm{i}}$ values were higher compared with the $\mathrm{ED}_{50} / K_{\mathrm{i}}$ ratio of compound 15 (Table 2). This finding suggests that an active mechanism is lowering the concentration of compounds 4,11 , and 14 at the site of action, resulting in increased $\mathrm{ED}_{50}$ values. The rapid hypotensive action of CB1 receptor agonists was shown to be primarily dependent on centrally mediated sympathetic tone (Vollmer et al., 1974), which could indicate that compounds 4,11 , and 14 but not 15 have higher $\mathrm{ED}_{50}$ values because they are less brain-permeable. Our in vitro data suggest that MRP4 might be involved. To draw definite conclusions about the involvement of MRP1-4 in influencing tissue concentrations of 3,4-diarylpyrazolines, in vivo studies should be performed using specific transport inhibitors and/or Mrp knockout mice.

In addition, it will be important to measure direct transport of CB1 receptor antagonists by MRP1-4 in vitro. Isolated membrane vesicles are probably not useful for this purpose because of the high nonspecific binding to lipid membranes and high passive diffusion of the lipophilic CB1 receptor antagonists (H. G. M. Wittgen, J. B. Koenderink, and F. G. M. Russel, unpublished results). Cell-based accumulation or vectorial transport studies may be more suitable. Furthermore, the role of the blood-brain barrier and intestinal $\mathrm{ABC}$ transporters $\mathrm{P}$-gp and breast cancer resistance protein (ABCG2) as possible $\mathrm{CB} 1$ receptor antagonist efflux pumps should be investigated. The role of influx transporters should also be considered in the tissue distribution of the $\mathrm{CB} 1$ receptor antagonists, but it is to be expected that uptake of these lipophilic compounds will be governed largely by passive diffusion.

In conclusion, we have shown that 3,4-diarylpyrazolines and rimonabant inhibited MRP1- and MRP4-mediated $\mathrm{E}_{2} 17 \beta \mathrm{G}$ transport and stimulated MRP2- and MRP3-mediated transport at low $\mathrm{E}_{2} 17 \beta \mathrm{G}$ concentrations. Stimulation of MRP2 and MRP3 shifted to inhibition at increasing substrate concentrations. The effect of these compounds on the transport activity of MRP1-4 shows the potential for possible drug-drug interactions. Preliminary in vivo data suggested that MRP4 could be involved in the lower brain permeability of some of the 3,4-diarylpyrazolines. The actual role of MRPs in tissue distribution of 3,4-diarylpyrazolines and rimonabant remains to be investigated. In addition, this study shows that the modulatory effects of the 3,4diarylpyrazolines were influenced by the properties of their $\mathrm{N}$-substituent, which indicates that small variations in their chemical structure can determine the affinity for the efflux transporters and thereby possibly affect their pharmacokinetic behavior.

\section{Acknowledgments}

We thank Tiny J. P. Adolfs from Abbott Healthcare Products B.V. (formerly Solvay Pharmaceuticals) for providing the in vivo pharmacology data. We also thank Dr. Kevin Weigl (Abbott Products $\mathrm{GmbH}$ ) for critical reading of the manuscript.

\section{Authorship Contributions}

Participated in research design: Wittgen, Dinter-Heidorn, Koenderink, and Russel.

Conducted experiments: Wittgen and van den Heuvel.

Contributed new reagents or analytic tools: van den Broek and DinterHeidorn.

Performed data analysis: Wittgen and van den Heuvel.

Wrote or contributed to the writing of the manuscript: Wittgen, Koenderink, and Russel.

\section{References}

Akita H, Suzuki H, Hirohashi T, Takikawa H, and Sugiyama Y (2002) Transport activity of human MRP3 expressed in Sf9 cells: comparative studies with rat MRP3. Pharm Res 19:34-41

Amundsen R, Asberg A, Robertsen I, Vethe NT, Bergan S, Hartmann A, and Midtvedt K (2009) Rimonabant affects cyclosporine A, but not tacrolimus pharmacokinetics in renal transplant recipients. Transplantation 87:1221-1224.

Bakos E, Evers R, Sinkó E, Váradi A, Borst P, and Sarkadi B (2000) Interactions of the human multidrug resistance proteins MRP1 and MRP2 with organic anions. Mol Pharmacol 57:760 768.

Barna I, Till I, and Haller J (2009) Blood, adipose tissue and brain levels of the cannabinoid ligands WIN-55,212 and SR-141716A after their intraperitoneal injection in mice: compoundspecific and area-specific distribution within the brain. Eur Neuropsychopharmacol 19:533541.

Bifulco M, Santoro A, Laezza C, and Malfitano AM (2009) Cannabinoid receptor CB1 antagonists: state of the art and challenges. Vitam Horm 81:159-189.

Bodó A, Bakos E, Szeri F, Varadi A, and Sarkadi B (2003a) Differential modulation of the human liver conjugate transporters MRP2 and MRP3 by bile acids and organic anions. J Biol Chem 278:23529-23537.

Bodó A, Bakos E, Szeri F, Váradi A and Sarkadi B (2003b) The role of multidrug transporters in drug availability, metabolism and toxicity. Toxicol Lett 140-141:133-143.

Boyd ST and Fremming BA (2005) Rimonabant-a selective CB1 antagonist. Ann Pharmacother 39:684-690.

Chen ZS, Lee K, and Kruh GD (2001) Transport of cyclic nucleotides and estradiol 17- $\beta$-Dglucuronide by multidrug resistance protein 4 . Resistance to 6-mercaptopurine and 6-thioguanine. J Biol Chem 276:33747-33754.

Conrad S, Kauffmann HM, Ito K, Deeley RG, Cole SP, and Schrenk D (2001) Identification of human multidrug resistance protein 1 (MRP1) mutations and characterization of a G671V substitution. J Hum Genet 46:656-663.

Di Marzo V (2008) CB1 receptor antagonism: biological basis for metabolic effects. Drug Discov Today 13:1026-1041.

El-Sheikh AA, van den Heuvel JJ, Koenderink JB, and Russel FG (2007) Interaction of nonsteroidal anti-inflammatory drugs with multidrug resistance protein (MRP) 2/ABCC2- and MRP4/ABCC4-mediated methotrexate transport. J Pharmacol Exp Ther 320:229-235.

El-Sheikh AA, van den Heuvel JJ, Krieger E, Russel FG, and Koenderink JB (2008) Functional role of arginine 375 in transmembrane helix 6 of multidrug resistance protein 4 (MRP4/ ABCC4). Mol Pharmacol 74:964-971.

Evers R, de Haas M, Sparidans R, Beijnen J, Wielinga PR, Lankelma J, and Borst P (2000) Vinblastine and sulfinpyrazone export by the multidrug resistance protein MRP2 is associated with glutathione export. Br J Cancer 83:375-383.

Flens MJ, Zaman GJ, van der Valk P, Izquierdo MA, Schroeijers AB, Scheffer GL, van der Groep P, de Haas M, Meijer CJ, and Scheper RJ (1996) Tissue distribution of the multidrug resistance protein. Am J Pathol 148:1237-1247.

Ito S, Ieiri I, Tanabe M, Suzuki A, Higuchi S, and Otsubo K (2001) Polymorphism of the ABC transporter genes, MDR1, MRP1 and MRP2/CMOAT, in healthy Japanese subjects. Pharmacogenetics 11:175-184. 
Jones D (2008) End of the line for cannabinoid receptor 1 as an anti-obesity target? Nat Rev Drug Discov 7:961-962.

Kanamaluru V, Lockwood G, Bonnet D, and Newton J (2005) Lack of effect of rimonabant on the pharmacokinetics of digoxin. J Clin Pharmacol 45:1081.

Kruh GD and Belinsky MG (2003) The MRP family of drug efflux pumps. Oncogene 22:75377552.

Lange JH, Coolen HK, van Stuivenberg HH, Dijksman JA, Herremans AH, Ronken E, Keizer HG, Tipker K, McCreary AC, Veerman W, et al. (2004) Synthesis, biological properties, and molecular modeling investigations of novel 3,4-diarylpyrazolines as potent and selective $\mathrm{CB}_{1}$ cannabinoid receptor antagonists. J Med Chem 47:627-643.

Lange JH, van Stuivenberg HH, Veerman W, Wals HC, Stork B, Coolen HK, McCreary AC, Adolfs TJ, and Kruse CG (2005) Novel 3,4-diarylpyrazolines as potent cannabinoid CB1 receptor antagonists with lower lipophilicity. Bioorg Med Chem Lett 15:4794-4798.

Leslie EM, Deeley RG, and Cole SP (2005) Multidrug resistance proteins: role of P-glycoprotein, MRP1, MRP2, and BCRP (ABCG2) in tissue defense. Toxicol Appl Pharmacol 204:216-237.

Loe DW, Almquist KC, Cole SP, and Deeley RG (1996) ATP-dependent $17 \beta$-estradiol 17-( $\beta$ D-Glucuronide) transport by multidrug resistance protein (MRP). Inhibition by cholestatic steroids. J Biol Chem 271:9683-9689.

Nies AT, Jedlitschky G, König J, Herold-Mende C, Steiner HH, Schmitt HP, and Keppler D (2004) Expression and immunolocalization of the multidrug resistance proteins, MRP1-MRP6 (ABCC1-ABCC6), in human brain. Neuroscience 129:349-360.

Nies AT and Keppler D (2007) The apical conjugate efflux pump ABCC2 (MRP2). Pflugers Arch 453:643-659.

Nissen SE, Nicholls SJ, Wolski K, Rodés-Cabau J, Cannon CP, Deanfield JE, Després JP, Kastelein JJ, Steinhubl SR, Kapadia S, et al. (2008) Effect of rimonabant on progression of atherosclerosis in patients with abdominal obesity and coronary artery disease: the STRADIVARIUS randomized controlled trial. JAMA 299:1547-1560.

Rao VV, Dahlheimer JL, Bardgett ME, Snyder AZ, Finch RA, Sartorelli AC, and PiwnicaWorms D (1999) Choroid plexus epithelial expression of MDR1 P glycoprotein and multidrug resistance-associated protein contribute to the blood-cerebrospinal-fluid drug-permeability barrier. Proc Natl Acad Sci USA 96:3900-3905.

Russel FG, Koenderink JB, and Masereeuw R (2008) Multidrug resistance protein 4 (MRP4/ ABCC4): a versatile efflux transporter for drugs and signalling molecules. Trends Pharmaco Sci 29:200-207.

Scheffer GL, Kool M, de Haas M, de Vree JM, Pijnenborg AC, Bosman DK, Elferink RP, van der Valk P, Borst P, and Scheper RJ (2002) Tissue distribution and induction of human multidrug resistant protein 3. Lab Invest 82:193-201.

Smeets PH, van Aubel RA, Wouterse AC, van den Heuvel JJ, and Russel FG (2004) Contribution of multidrug resistance protein 2 (MRP2/ABCC2) to the renal excretion of $p$-aminohippurate
(PAH) and identification of MRP4 (ABCC4) as a novel PAH transporter. J Am Soc Nephrol 15:2828-2835.

Tam J, Vemuri VK, Liu J, Bátkai S, Mukhopadhyay B, Godlewski G, Osei-Hyiaman D, Ohnuma S, Ambudkar SV, Pickel J, et al. (2010) Peripheral CB1 cannabinoid receptor blockade improves cardiometabolic risk in mouse models of obesity. J Clin Invest 120:2953-2966.

Turpault S, Kanamaluru V, Lockwood GF, Bonnet D, and Newton J (2006) Rimonabant pharmacokinetics in healthy and obese subjects. Clin Pharmacol Ther 79:50.

Van Aubel RA, Hartog A, Bindels RJ, Van Os CH, and Russel FG (2000) Expression and immunolocalization of multidrug resistance protein 2 in rabbit small intestine. Eur J Pharmacol 400:195-198.

Van Aubel RA, Koenderink JB, Peters JG, Van Os CH, and Russel FG (1999) Mechanisms and interaction of vinblastine and reduced glutathione transport in membrane vesicles by the rabbit multidrug resistance protein Mrp2 expressed in insect cells. Mol Pharmacol 56:714-719.

van Aubel RA, Smeets PH, Peters JG, Bindels RJ, and Russel FG (2002) The MRP4/ABCC4 gene encodes a novel apical organic anion transporter in human kidney proximal tubules: putative efflux pump for urinary cAMP and cGMP. J Am Soc Nephrol 13:595-603.

Vollmer RR, Cavero I, Ertel RJ, Solomon TA, and Buckley JP (1974) Role of the central autonomic nervous system in the hypotension and bradycardia induced by ( - )- $\Delta 9$-transtetrahydrocannabinol. J Pharm Pharmacol 26:186-192.

Yu XQ, Xue CC, Wang G, and Zhou SF (2007) Multidrug resistance associated proteins as determining factors of pharmacokinetics and pharmacodynamics of drugs. Curr Drug Metab 8:787-802.

Zelcer N, Huisman MT, Reid G, Wielinga P, Breedveld P, Kuil A, Knipscheer P, Schellens JH, Schinkel AH, and Borst P (2003) Evidence for two interacting ligand binding sites in human multidrug resistance protein 2 (ATP binding cassette C2). J Biol Chem 278:23538-23544.

Zeng H, Liu G, Rea PA, and Kruh GD (2000) Transport of amphipathic anions by human multidrug resistance protein 3. Cancer Res 60:4779-4784.

Zhou SF, Wang LL, Di YM, Xue CC, Duan W, Li CG, and Li Y (2008) Substrates and inhibitors of human multidrug resistance associated proteins and the implications in drug development. Curr Med Chem 15:1981-2039.

Address correspondence to: Dr. F. G. M. Russel, Department of Pharmacology and Toxicology (149), Radboud University Nijmegen Medical Centre, Nijmegen Centre for Molecular Life Sciences, P.O. Box 9101, 6500 HB Nijmegen, The Netherlands. E-mail: f.russel@pharmtox.umcn.nl 